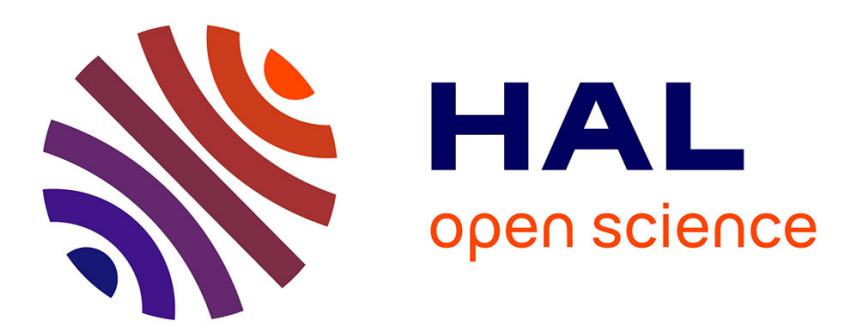

\title{
Identification of the low-altitude cusp by Super Dual Auroral Radar Network radars: A physical explanation for the empirically derived signature
}

\author{
R. Andre, M. Pinnock, A.S. Rodger
}

\section{- To cite this version:}

R. Andre, M. Pinnock, A.S. Rodger. Identification of the low-altitude cusp by Super Dual Auroral Radar Network radars: A physical explanation for the empirically derived signature. Journal of Geophysical Research Space Physics, 2000, 105 (A12), pp.81 - 108. 10.1029/2000JA900071 . insu03002185

\section{HAL Id: insu-03002185}

https://hal-insu.archives-ouvertes.fr/insu-03002185

Submitted on 12 Nov 2020

HAL is a multi-disciplinary open access archive for the deposit and dissemination of scientific research documents, whether they are published or not. The documents may come from teaching and research institutions in France or abroad, or from public or private research centers.
L'archive ouverte pluridisciplinaire HAL, est destinée au dépôt et à la diffusion de documents scientifiques de niveau recherche, publiés ou non, émanant des établissements d'enseignement et de recherche français ou étrangers, des laboratoires publics ou privés. 


\title{
Identification of the low-altitude cusp by Super Dual Auroral Radar Network radars: A physical explanation for the empirically derived signature
}

\author{
R. André, ${ }^{1}$ M. Pinnock, and A. S. Rodger \\ British Antarctic Survey, Natural Environment Research Council, Cambridge, England
}

\begin{abstract}
The Super Dual Auroral Radar Network (SuperDARN) radars are proving to be a very powerful experimental tool for exploring solar wind-magnetosphere-ionosphere interactions. They measure the autocorrelation function (ACF) of the signal backscattered from ionospheric irregularities, and they derive parameters such as the Doppler velocity and the spectral width. The associated spectra have a specific behavior inside the cusp, a strong temporal and spatial evolution of the velocity and spectral width, and a high value of the spectral width. Until now, no studies have explained these characteristics, but they are routinely used to detect the cusp in the radar data, for example, to estimate the location of the open/closed field line boundary. Both satellite and ground-based magnetometer data from the cusp region show broadband wave activity in the Pc1 and Pc2 frequency band. In this study we evaluate how such wave activity modifies the radar's ACF, and we conclude that it explains the spectra seen in the cusp. More specifically, we find that (1) even a monochromatic electric field variation can cause apparently turbulent behavior, including wide spectral widths and apparent multiple components, (2) even low-amplitude waves are capable of causing large spectral widths, if the frequency is sufficiently high, (3) for a fixed low-amplitude electric field variation the measured spectral width increases with wave frequency, displaying a sharp transition from low to high spectral width above an onset frequency, and (4) the determination of the background velocity field is not strongly affected by such conditions. While the wave activity is shown to have a major impact on the spectral width, it is found that the radar does accurately represent the large-scale plasma velocity.
\end{abstract}

\section{Introduction}

Identification of the ionospheric signature of the cusp is important for many studies of solar wind-magnetosphereionosphere coupling processes. For example, the cusp signature is a proxy for the open/closed field line boundary on the dayside, and flow across this boundary is a measure of the reconnection rate at the magnetopause [Baker et al., 1997]. Several techniques have been used for identifying the cusp at low altitudes, the most widely accepted being the signature of cusp particle precipitation in polar-orbiting satellites such as Defense Meteorological Satellite Program (DMSP) [Newell and Meng, 1988], but ground-based magnetometer signatures [Menk et al., 1992] have also been used. HF radar data have been found to contain a distinctive signature of the

\footnotetext{
'Now at Laboratoire de Physique et Chimie de l'Environnement, Centre National de la Recherche Scientifique, Orléans, France.
}

Copyright 2000 by the American Geophysical Union.

Paper number 2000JA900071.

0148-0227/00/2000JA900071\$09.00 low-altitude cusp [e.g., Baker et al., 1995], but the physical explanation has remained elusive. It is the topic of this paper.

From the transmission of a multiple-pulse scheme the Super Dual Auroral Radar Network (SuperDARN) radars [Greenwald et al., 1995] measure the autocorrelation function (ACF) of the signal backscattered at several distances (range gates) from the radar by field-aligned electron concentration irregularities. In each range gate, this ACF is routinely analyzed by a basic method (called FITACF) [Villain et al., 1987; Baker et al., 1995, Appendix A] which extracts the power, the line-of-sight Doppler velocity of the irregularities, and the spectral width. Baker et al. [1995] have found that the ACFs recorded in the cusp have a very particular behavior. They showed that the Doppler velocity spectrum observed in the cusp, which was detected from the particle characteristics [Newell and Meng, 1988] recorded by a DMSP satellite, presents several overlapping components from which a high spectral width value is determined. Although no studies have explained this behavior, the cusp could easily be identified in the radar data by a high and variable spectral width, and variable line-of-sight velocity [Pinnock et al., 1995]. 
Intense wave activity has been observed when satellites pass through the cusp [see, e.g., Maynard et al., 1991]. Matsuoka et al. [1993], and later Erlandson and Anderson [1996], have clearly shown a step-like increase of wave activity in the frequency band $0.2-2.2 \mathrm{~Hz}$ with electric field values of a few $\mathrm{mV} \mathrm{m}^{-1}$, coincident with the equatorward edge of the cusp particle precipitation. These waves appear to result from a superposition of an electrostatic noise and electromagnetic waves. On the ground the electromagnetic part of this wave activity in the Pc1 and Pc2 wave band has been recorded by magnetometers, as shown, for example, by Menk et al. [1992] and Dyrud et al. [1997], although there is some contradiction in these two studies as to the latitude at which the waves are observed.

In this paper we evaluate the effect of such a time-varying electric field component on the determination of the radar $\mathrm{ACF}$, and we extend the results recently published [André et al., 1999]. In section 2 a detailed description of the wave activity as seen on board satellites and on the ground in the cusp region is given. The characteristics of the HF radar data obtained in the cusp are also discussed. Simulating the radar operating mode, section 3 shows that a monochromatic wave (Pc1) of realistic amplitude for the cusp region can affect the radar signal processing such as to increase the radar spectral width. This result is then extended to a more realistic wave activity by considering the case of a narrow band wave. The sources of these waves in the magnetosphere are then discussed, and we conclude that they can explain the high spectral width values observed in radar spectra from the morning sector and especially in the cusp.

\section{Wave Observations in the Cusp}

\subsection{Satellite Data}

The low-altitude cusp has been defined from the particle data [Newell and Meng, 1988, p. 14550] as a "localized region in which magnetosheath plasma entry is more direct." In this region the particles have to maintain their original (magnetosheath) spectral characteristics with a high number flux. Newell and Meng [1988, 1989, 1992] and Newell et al. [1989] use a large number of DMSP satellite passes to derive a particle definition of the cusp and its statistical position depending on the interplanetary magnetic field (MMF) conditions.

Using the Dynamic Explorer 2 (DE 2) data, Curtis et al. [1982] and Maynard [1985] showed broadband electrostatic noise activity in the ULF/ELF frequency band (from a few hertz to kilohertz) associated with the cusp, as identified by particle data. The electric field amplitude is found to be of the order of a few tens of $\mathrm{mV} \mathrm{m}^{-1}$ but can sometimes reach $100 \mathrm{mV} \mathrm{m}^{-1}$. Later, Maynard et al. [1991] detected a lowfrequency $(<1 \mathrm{~Hz})$ wave component in both the electric and magnetic field. By using the particle data, they also found that these electric field structures correspond to the equatorward edge of the cusp. Erlandson and Anderson [1996] found that the power spectral density of the electric field in the $\mathrm{Pc} 1$ frequency band sharply increases at the equatorward edge of the cusp particle precipitation. Equatorward of this step-like increase of the power spectrum, they found an increase of the electrostatic noise power, which limits their Pc1 detection. Studying the magnetic component, they showed that the electric to magnetic field ratio strongly suggests an Alfvénic behavior of these waves.

At higher altitude, Matsuoka et al. [1991, 1993] observed a similar electromagnetic wave activity in the Exos-D satellite data, and they showed that the electric fluctuations in the cusp are more intense than those observed in the dayside auroral region. They showed a very good correlation between the latitude of the increase of the power spectral density in the Pc1-Pc2 frequency band and the increase of the magnetosheath particle flux in the cusp. They also found that these fluctuations are consistent with an Alfvén wave interpretation.

\subsection{Magnetometer Data}

By using several ground stations, Bolshakova et al. [1980] found that the $\mathrm{Pc} 1-\mathrm{Pc} 2$ occurrence is a maximum when the equatorward edge of the cusp is close to a station. Later, Morris and Cole [1991] and especially Menk et al. [1992] separate these waves into several categories and found that narrowband Pc1-Pc2 waves are mostly observed a few degrees equatorward of the plasma sheet boundary layer in the noon sector and that the unstructured wideband emissions $(0.1-0.4 \mathrm{~Hz})$ are observed mostly within $2^{\circ}$ of the poleward edge of the cusp. The latter wave type was observed for a duration consistent with the typical longitudinal width of the cusp region. Dyrud et al. [1997, 1998] found that the $\mathrm{Pc} 1-\mathrm{Pc} 2$ bandwidth varies with latitude in the cusp: The high-latitude stations tend to observe more diffuse wideband waves whereas lower-latitude stations tend to observe more discrete narrowband waves. They suggest that these waves may have different energy sources from the ones recorded on board satellites.

\section{HF Radar Observations of the Cusp}

It is well known that the SuperDARN radars' ACFs recorded in the cusp have a very particular behavior. Baker et al. [1990, 1995] showed that the Doppler velocity spectrum observed in the cusp shows multiple components. Figure 2 of Baker et al. [1995] shows that these spectra are not well correlated from gate to gate. While the main component may be approximately constant across several range gates, the other components do not show any strong coherence with range. Baker et al. [1995, p. 7675] described these spectra as a "reflection of complex temporal and spatial behavior of the structures involved in the scattering process". They also suggest that these spectra contain several discrete components that are too close together to be resolved.

Published data show that the temporal velocity variation in one range gate is much higher inside the cusp than it is outside [Pinnock et al., 1995, Figure 2]. This effect is consistent with the presence of multicomponent spectra. Because the signal processing algorithm, FITACF, deduces the line-of-sight velocity by applying a linear fit on the temporal evolution of the ACF phase, and because a multicomponent 
spectrum induces a nonlinear evolution of this phase, one can expect a large error associated with this fit. This consideration can easily be checked by plotting the values of the standard deviation associated with the phase fit, and one can find that this parameter is strongly enhanced inside the cusp. This last parameter provides a quick check on the nonlinear behavior of the phase and also on the probability of finding several components in the spectrum (with the proviso that this test should only be applied to data which have a large signal-to-noise ratio).

Inside the cusp the spectral width, as determined by FITACF, is very high (greater than $150 \mathrm{~m} \mathrm{~s}^{-1}$ ) and highly variable. As discussed by Baker et al. [1995], these spectral widths could not be physically interpreted, because of the spectrum characteristics cited above. When the spectrum contains several components, the FITACF method cannot resolve the width of the main component but usually gives an overestimation of it (i.e., the spectral width does not represent the full width at half power of a single component). The spectral width variability might then be assumed to be coming from the dynamics of the spectra. Nonetheless, the characteristic large spectral width has been a useful characteristic for determining the equatorward edge of the cusp particle precipitation and has been used in many studies. Thus the cusp can easily be identified in the radar data by a high and variable spectral width, a variable velocity, and a large standard deviation associated with the linear fit performed on the phase.

\section{Time-Varying Electric Field}

Satellite data clearly show the onset of strong wave activity in the ionospheric cusp, in the frequency band $0.1-5 \mathrm{~Hz}$, and that the wave amplitude can easily reach a few $\mathrm{mV} \mathrm{m}^{-1}$. This implies an amplitude of the velocity field fluctuation of the order of $50 \mathrm{~m} \mathrm{~s}^{-1}$. This contrasts with the background convection velocity which may give rise to line-of-sight velocity components of $1000 \mathrm{~m} \mathrm{~s}^{-1}$. Here we study in more detail the effect of the wave activity on the radar ACFs. We first give a phenomenological approach to this question and a description of the simulation performed. Then we investigate the effect of a monochromatic and a more realistic narrow band wave.

\subsection{Methodology}

To compute an ACF, a SuperDARN radar emits a pattern of pulses which are not evenly spaced and receives the backscattered signal from ionospheric irregularities [Greenwald et al., 1985]. After $\sim 75 \mathrm{~ms}$, the radar halts sounding and computes the ACF of the signal backscattered from each range. Then, in order to reduce the noise level, the radar repeats the previous sequence and integrates this ACF over 50 identical cycles (for the integration time used in the highresolution radar running mode). One considers that each individual ACF (before the integration) contains the line-ofsight velocity information associated with that epoch. If we assume that the velocity field varies between these cycles, then the integrated ACF will reflect the velocity distribution found during this time. Thus, by considering a modulated velocity field during the integration time, one can expect that the Fourier transform of the resulting ACF should not exhibit one narrow component. This mechanism suggests that such a time-varying electric field could affect the spectrum, and it gives rise to the observed multicomponent spectra in the cusp.

The combination of the low amplitude of the wave compared to the typical line-of-sight velocity, the averaging of the ACFs over the integration period, the radar halt period for signal processing (which introduces a variable time delay in the sampling), and the precise details of the software algorithm that processes these ACFs to derive the velocity and spectral widths (FITACF), makes it difficult to predict exactly what the impact of such wave activity is. To address this question, we have built a simulator. We consider only one range gate in which all the scatterers are randomly distributed. All the scatterers are totally correlated, and thus turbulence effects are not considered: For a velocity arising from a constant electric field $\left(\vec{v}=\vec{E} \times \vec{B} / \mathrm{B}^{2}\right)$, we have zero spectral width. For each pulse the $F$ region irregularities will backscatter the signal $S(t)$ given by (1):

$$
\begin{gathered}
S(t)=\sum_{i}^{N} e^{-j \cdot \vec{k} \cdot \vec{r}_{i}(t)}, \\
\vec{r}_{i}(t)=\vec{r}_{0}+\vec{V}(t) \cdot t, \\
\vec{V}(t)=\vec{V}_{0}+\vec{V}_{1} \cdot \sum_{k=1}^{M} \cos \left(2 \cdot \pi \cdot f_{k} \cdot t+\phi_{k}\right),
\end{gathered}
$$

where $\vec{k}$ is the radar wave vector, $\vec{r}_{i}(t)$ is the position of the irregularity, $\vec{r}_{0}$ is their position at $t=0$, and $\vec{V}(t)$ is the velocity coming from both the large-scale convection $\left(\vec{V}_{0}\right)$ and the wave experienced in the cusp. The summation is over the number of scatterers $(N)$. The wave is defined by a superposition of $M$ monochromatic sources which have (1) a Gaussian frequency distribution, centered around a mean value and with a defined bandwidth, (2) a uniform distribution of phases, and (3) a common amplitude $\left(\vec{V}_{1}\right)$. This large number of source should give us a- representative signature of the wave activity seen inside the cusp.

We use the multipulse scheme typically used by the radars [Barthes et al., 1998, Figure 1] and compute the individual ACFs, average them over the integration period, and then submit the final ACF to the routine fitting procedure (FITACF) which determines the velocity and spectral width in an identical way to that for the SuperDARN observations. The simulations are for the radar running in a high-resolution mode with 5-s integration time, which typically allows 47 individual ACFs from which the integrated ACF is produced, but the results obtained are still valid when considering a normal radar running mode with an integration time of $7 \mathrm{~s}$.

\subsection{Monochromatic Waves}

In this part we consider only the case of a monochromatic source: The velocity defined in (1) is composed of only one source $(M=1)$.

4.2.1. Autocorrelation function. Figure 1 gives an example of a simulated ACF when considering a monochro- 

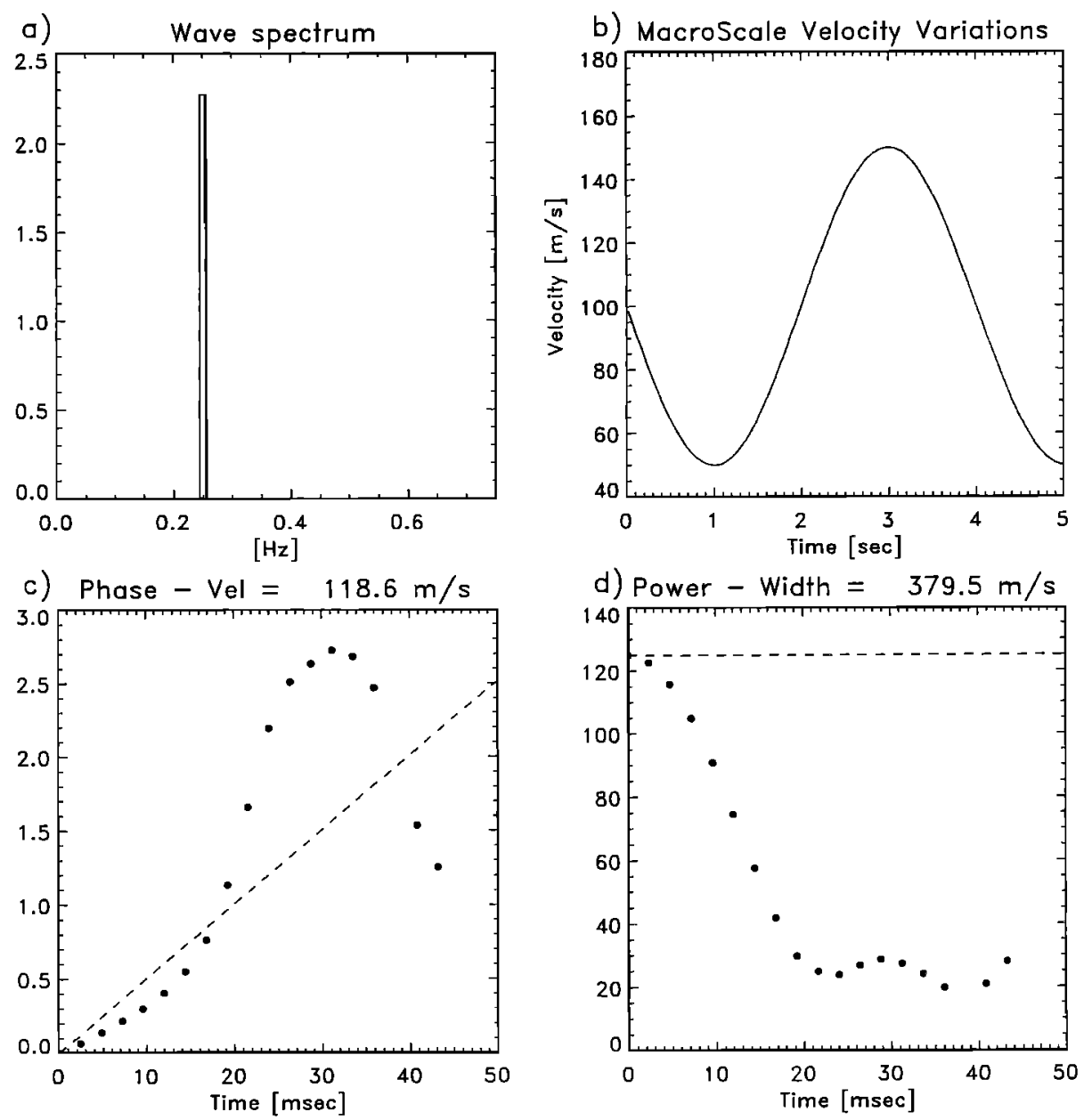

Figure 1. (a) Spectrum of the monochromatic wave used, (b) Velocity variation during the radar integration time, (c) Phase of the simulated autocorrelation function (ACF), (d) Power of the simulated ACF.

matic wave defined by an amplitude of $50 \mathrm{~m} \mathrm{~s}^{-1}$, a frequency of $0.250 \mathrm{~Hz}$, and $90^{\circ}$ phase offset $\left(\phi_{k}\right)$, in a background plasma velocity of $100 \mathrm{~m} \mathrm{~s}^{-1}$ along the radar beam direction. The wave frequency spectrum and the induced velocity variation during the integration time are shown in Figures $1 \mathrm{a}$ and $\mathrm{lb}$, respectively, and the temporal evolution of the phase and power of the ACFs are plotted in Figure $1 \mathrm{c}$ and 1d, respectively. If the velocity spectrum comprised a single component, it would produce a linear progression of phase with time (lag), as shown by the dotted line. The phase progression is not linear. This modulation, also seen in the power, suggests that the spectrum associated with this $\mathrm{ACF}$ contains several velocity components. A Fourier analysis (not shown) shows a spectrum with several velocity components which can be different from those experienced by the irregularities, and these components are therefore artefacts of the data processing. This spectrum is very similar to those published by Baker et al. [1995]. The velocity deduced from the phase $\left(118 \mathrm{~m} \mathrm{~s}^{-1}\right)$ is close to the defined background velocity $\left(100 \mathrm{~m} \mathrm{~s}^{-1}\right)$, but despite the fact that there is no turbulent effect in this simulation, such a temporal variation of the electric field introduces a spectral width of $376 \mathrm{~m} \mathrm{~s}^{-1}$.
4.2.2. Velocity aliasing. Figure $2 a$ shows the velocity found by FITACF as a function of varying the wave phase $\left(\phi_{k}\right)$ in (1). The upper curve corresponds to a velocity modulation with an amplitude of $50 \mathrm{~m} \mathrm{~s}^{-1}$, a frequency of $0.5 \mathrm{~Hz}$ in a background velocity of $200 \mathrm{~m} \mathrm{~s}^{-1}$, whereas the lower curve results from a wave which has an amplitude and a frequency of $50 \mathrm{~m} \mathrm{~s}^{-1}$ and $0.15 \mathrm{~Hz}$, respectively, in a background plasma velocity of $75 \mathrm{~m} \mathrm{~s}^{-1}$. The bars show the errors on the velocity determined by the FITACF method. The velocity is seen to vary with the wave phase, but it is still inside the velocities experienced by the scatterers (e.g., $200 \pm$ $50 \mathrm{~m} \mathrm{~s}^{-1}$ ), whatever the background velocity used. The velocity errors are less than $30 \mathrm{~m} \mathrm{~s}^{-1}$ and do not seem to vary with the frequency of the wave, but they can be much smaller for some phase shifts. The main feature of these curves is the bimodal characteristic of the derived velocity values, seen particularly clearly in the case for a background flow of $75 \mathrm{~m}$ $\mathrm{s}^{-1}$. The derived velocity values switch rapidly, for a small change in phase, between an upper and lower velocity value. We next explore the consequences of this behavior.

With such a wave model, one can produce time series of ionospheric velocity variations from which the ACFs can be computed (with the radar running in a high-resolution mode: 


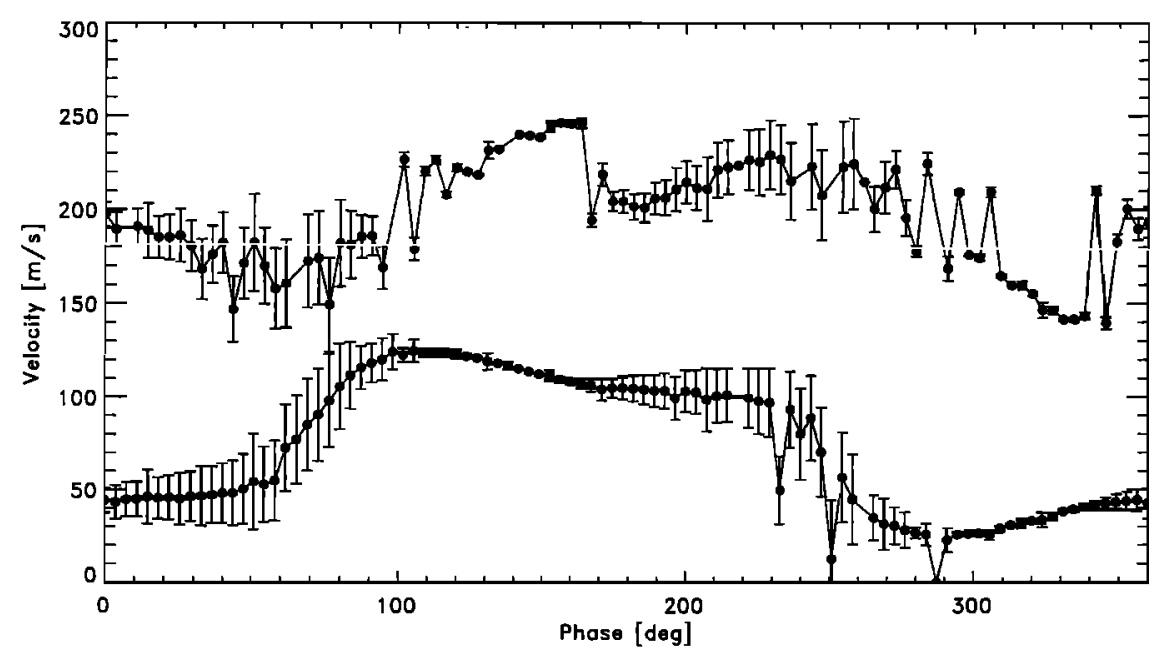

a)

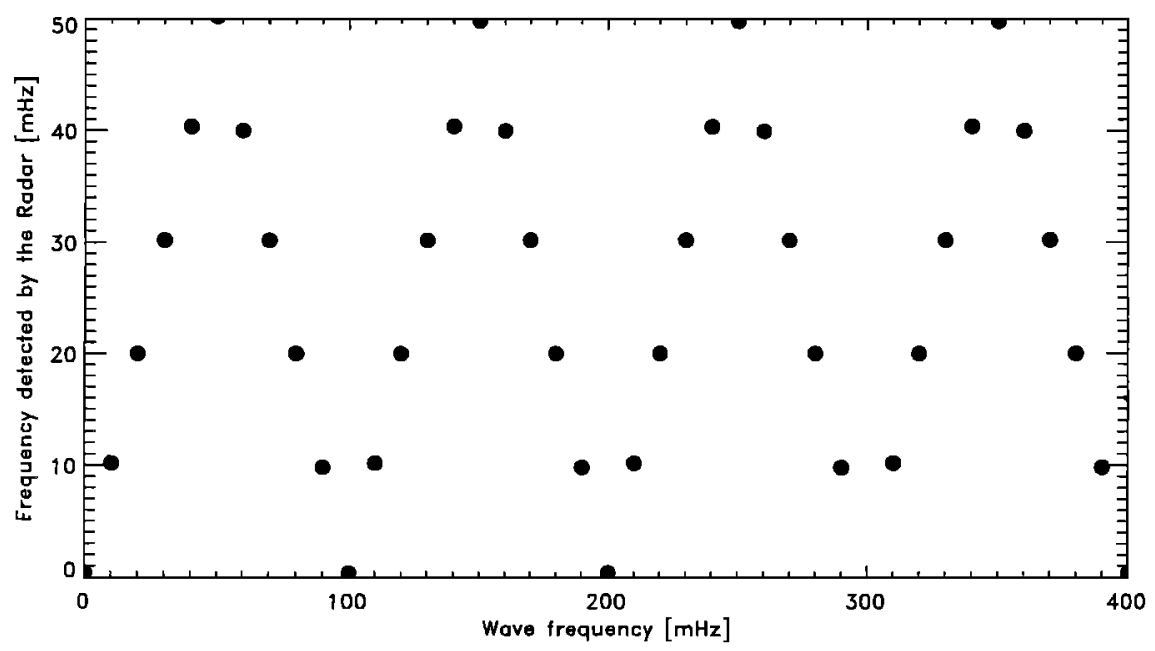

b)

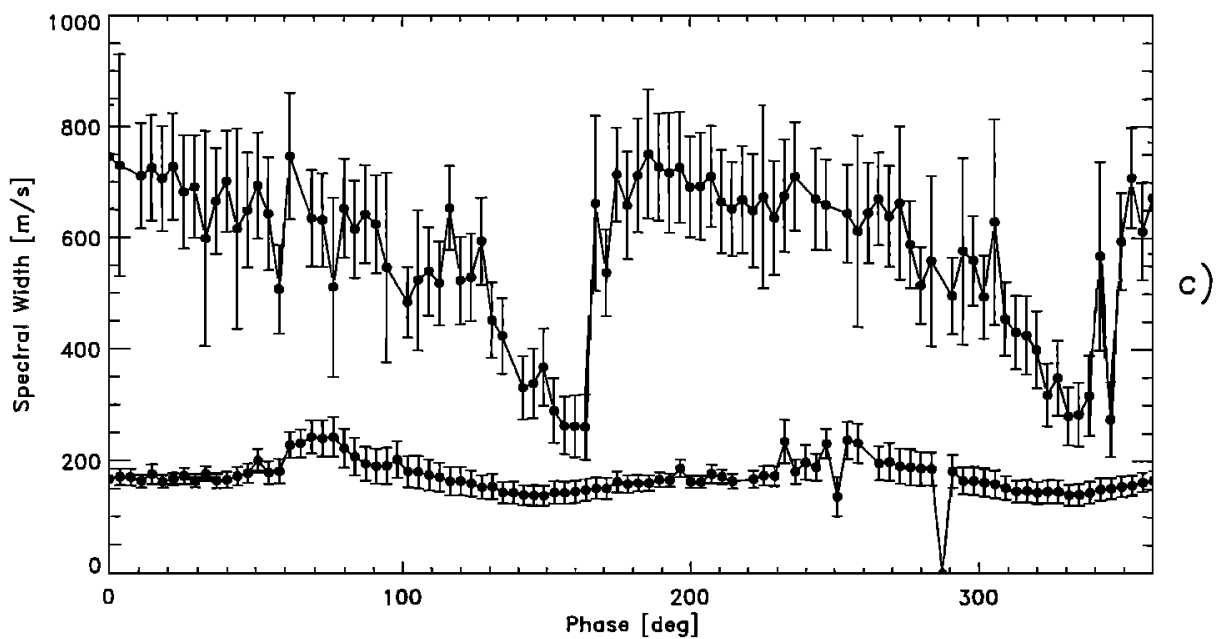

Figure 2. (a) Velocity determined by the standard method called FITACF as a function of the wave phase for a wave frequency and amplitude of $0.15 \mathrm{~Hz}$ and $50 \mathrm{~m} \mathrm{~s}^{-1}$, respectively, for the lower curve and of 0.5 and $50 \mathrm{~m} \mathrm{~s}^{-1}$ for the upper curve. The background velocities are 200 and $75 \mathrm{~m} \mathrm{~s}^{-1}$ for the upper curve and the lower curve, respectively. (b) Fluctuation frequency of the determined velocity as a function of the wave frequency. (c) As in Figure $2 a$ but for the spectral width.

5 -s integration time, with a temporal resolution of $10 \mathrm{~s}$ ) and finally arrive at the velocities determined by the radar for each integration period. Because the phase of the wave will vary between two successive integration times, the computed velocity will be different, and hence one might expect a modulation in the velocities determined by the radar.

Figure $2 b$ presents the modulation frequency discussed above as a function of the wave frequency used in the simu- 


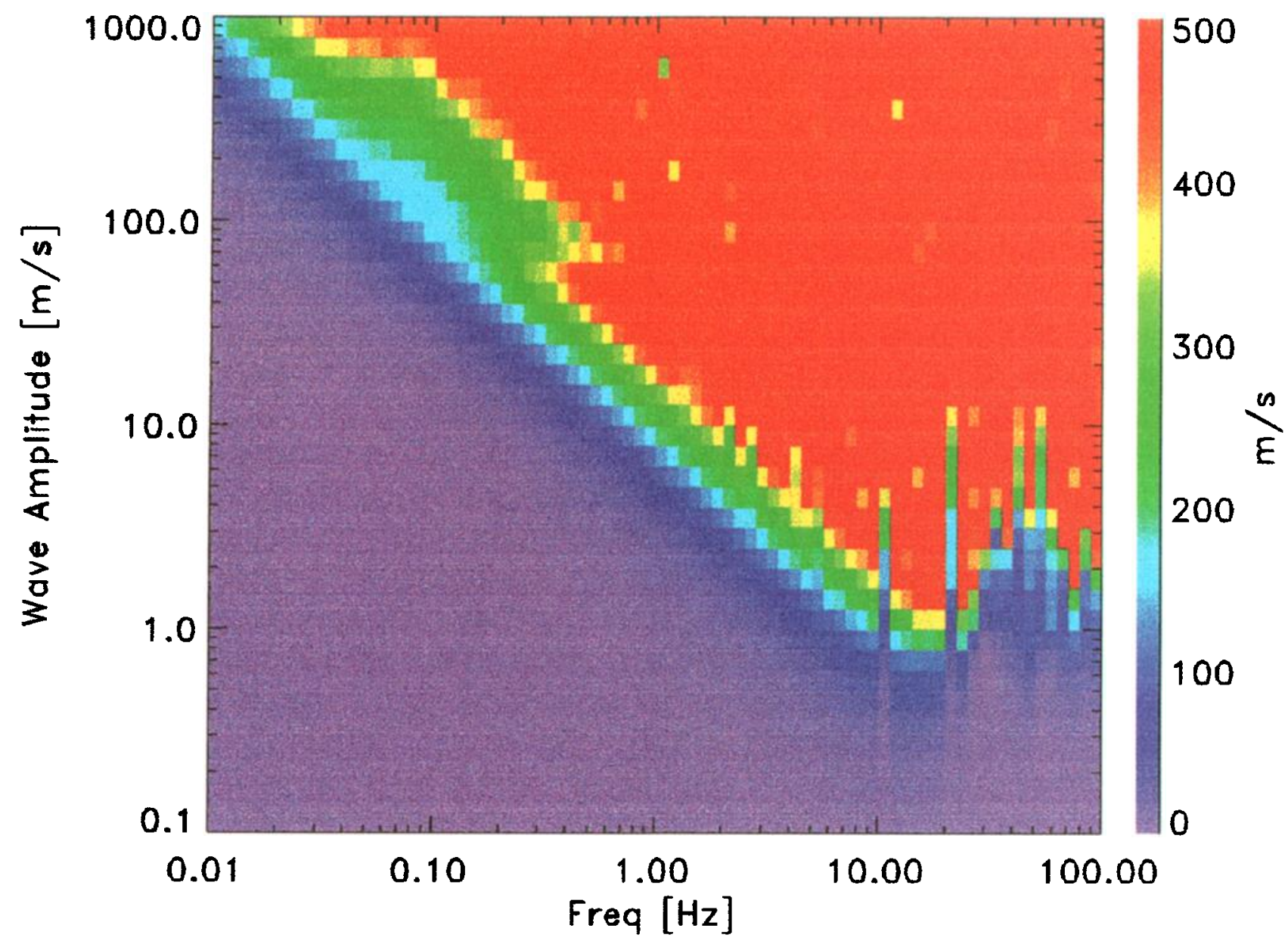

Plate 1. Color-coded spectral width as a function of the wave amplitude and wave frequency.

lation. Figure $2 \mathrm{~b}$ shows a typical aliasing effect in the velocity determination. In the radar's high-resolution mode the temporal resolution gives a Nyquist frequency of $50 \mathrm{mHz}$. In the common radar running mode the temporal resolution of the velocity is $2 \mathrm{~min}$, which implies a Nyquist frequency of $4 \mathrm{mHz}$. All the waves which have a frequency lower than the Nyquist frequency are correctly resolved by the radar, but the highest frequency waves are undersampled. Thus a typical Pcl wave could be seen as a Pc5 wave in the radar data. We stress that this behavior can only be demonstrated for a monochromatic $\mathrm{Pcl}$ wave.

Figure $2 c$ shows the spectral width as a function of the wave phase. When the wave frequency is $0.15 \mathrm{~Hz}$ (lower curve), the spectral width is nearly constant around $200 \mathrm{~m}$ $\mathrm{s}^{-1}$, with a small error $\left(\leq 50 \mathrm{~m} \mathrm{~s}^{-1}\right)$. When the frequency increases (upper curve is for $0.5 \mathrm{~Hz}$ ), the spectral width values increase and become much more variable with phase, covering the range $200-900 \mathrm{~m} \mathrm{~s}^{-1}$, and their associated errors are higher, reaching $100 \mathrm{~m} \mathrm{~s}^{-1}$. In summary, Figure 2 shows that the radar determines a velocity value which is representative of the convection conditions (i.e., within the background velocity value and the wave amplitude), but the spectral width determined is strongly dependent on the frequency of the perturbing wave.
4.2.3. High spectral width. Plate 1 shows the mean spectral width values (color-coded) as a function of the wave frequency and wave amplitude. For each possible combination of frequency and amplitude the temporal variability of the ionospheric plasma velocity has been determined for a set period of time, and then this time series has been passed through the simulator. The resulting ACFs are then analyzed by FITACF, and spectral width values are produced. Thus, for a given wave frequency and amplitude, one has a spectral width distribution that is representative of the different wave phase encountered and its mean value over the set period of time.

Plate 1 shows a sharp transition between low and high spectral width. For example, when the wave amplitude is of the order of $20 \mathrm{~m} \mathrm{~s}^{-1}$ (corresponding to an electric field of $1 \mathrm{mV} \mathrm{m}^{-1}$ ), a high mean spectral width value (greater than $200 \mathrm{~m} \mathrm{~s}^{-1}$ ) is obtained when considering a wave frequency greater than $0.8 \mathrm{~Hz}$. When the wave frequency increases still further, the mean spectral width reaches a saturation level at around $650 \mathrm{~m} \mathrm{~s}^{-1}$. Correspondingly, for a given wave frequency a greater spectral width value is obtained with increasing wave amplitude.

The main property of this result is that except for lowfrequency $(f<0.5 \mathrm{~Hz})$ and large amplitude $\left(V_{1}>\right.$ 
$80 \mathrm{~m} \mathrm{~s}^{-1}$ ) waves, the transition from low to high spectral width is sharp and occurs for low-amplitude waves (for example, at $20 \mathrm{~m} \mathrm{~s}^{-1}=1 \mathrm{mV} \mathrm{m}^{-1}$ for $0.5 \mathrm{~Hz}$ ). For lowerfrequency waves the high spectral width regime is obtained more progressively and for higher wave amplitude $(200 \mathrm{~m}$ $\mathrm{s}^{-1}=10 \mathrm{mV} \mathrm{m}^{-1}$ for $0.1 \mathrm{~Hz}$ ).

\subsection{Narrowband Wave}

Waves seen on the ground near the cusp have a bandwidth of the order of $0.2 \mathrm{~Hz}$ [Dyrud et al., 1997], which is narrower near the equatorward edge of the cusp and wider on its poleward edge. This suggests that a more realistic simulation would be to consider the case of a narrowband electric field. To achieve this, the spectrum is simulated by the addition of 500 monochromatic waves which have the same amplitude. The distribution function of the wave frequencies is then centered around a main frequency and is characterized by a spectral width.

4.3.1. Time series. From this wave model, one can generate long time series (10 $\mathrm{min}$ ) of ionospheric plasma velocities and compute the velocity and the spectral width. Figure 3 shows on the upper panel an example of a time-varying electric field generated by this simulation. Here the mean wave amplitude, wave frequency, and band width are 2.5 $\mathrm{mV} \mathrm{m} \mathrm{m}^{-1}$ (which corresponds to a velocity of $50 \mathrm{~m} \mathrm{~s}^{-1}$ ), $0.5 \mathrm{~Hz}$, and $0.3 \mathrm{~Hz}$, respectively. The background line-ofsight velocity is set to $500 \mathrm{~m} \mathrm{~s}^{-1}$. Examining the ACF phase plots (not shown) produced for each integration period from this simulation shows a strong nonlinear behavior, suggesting that the spectra associated with these ACFs contain several components. The middle and lower panels of Figure 3 show the Doppler velocity (middle panel) and the spectral width (lower panel) values produced by the radar's signal processing. The error bars show the statistical uncertainties associated with these parameters, derived by the standard fitting procedure (FITACF). Figure 3 illustrates well the variability obtained in both the Doppler velocity and the spectral width, and the high spectral width values $\left(\approx 400 \mathrm{~m} \mathrm{~s}^{-1}\right)$.

These variations are typical of the radar data seen in the cusp. For example, Figure 4 shows the line-of-sight velocity (upper panel) and the spectral width (lower panel) recorded by the Halley SuperDARN radar during $10 \mathrm{~min}$, in two different range gates located inside and equatorward of the cusp (the upper and lower curves, respectively). The upper curve has been shifted by $500 \mathrm{~m} \mathrm{~s}^{-1}$ for clarity and shows a highly variable spectral width, with an average value of $400 \mathrm{~m} \mathrm{~s}^{-1}$, in good agreement with the simulated results (Figure 3).

4.3.2. Wave amplitude effect. We next show the generality of the results obtained in Figure 3 by varying both the background line-of-sight velocity and the amplitude of the perturbing wave. From such time series, one can compute the mean Doppler velocity and spectral width with their corresponding standard deviations, when considering a particular wave frequency and bandwidth 0.5 and $0.235 \mathrm{~Hz}$, respectively) for several wave amplitudes.

Figure 5 (left) shows the mean velocity as a function of

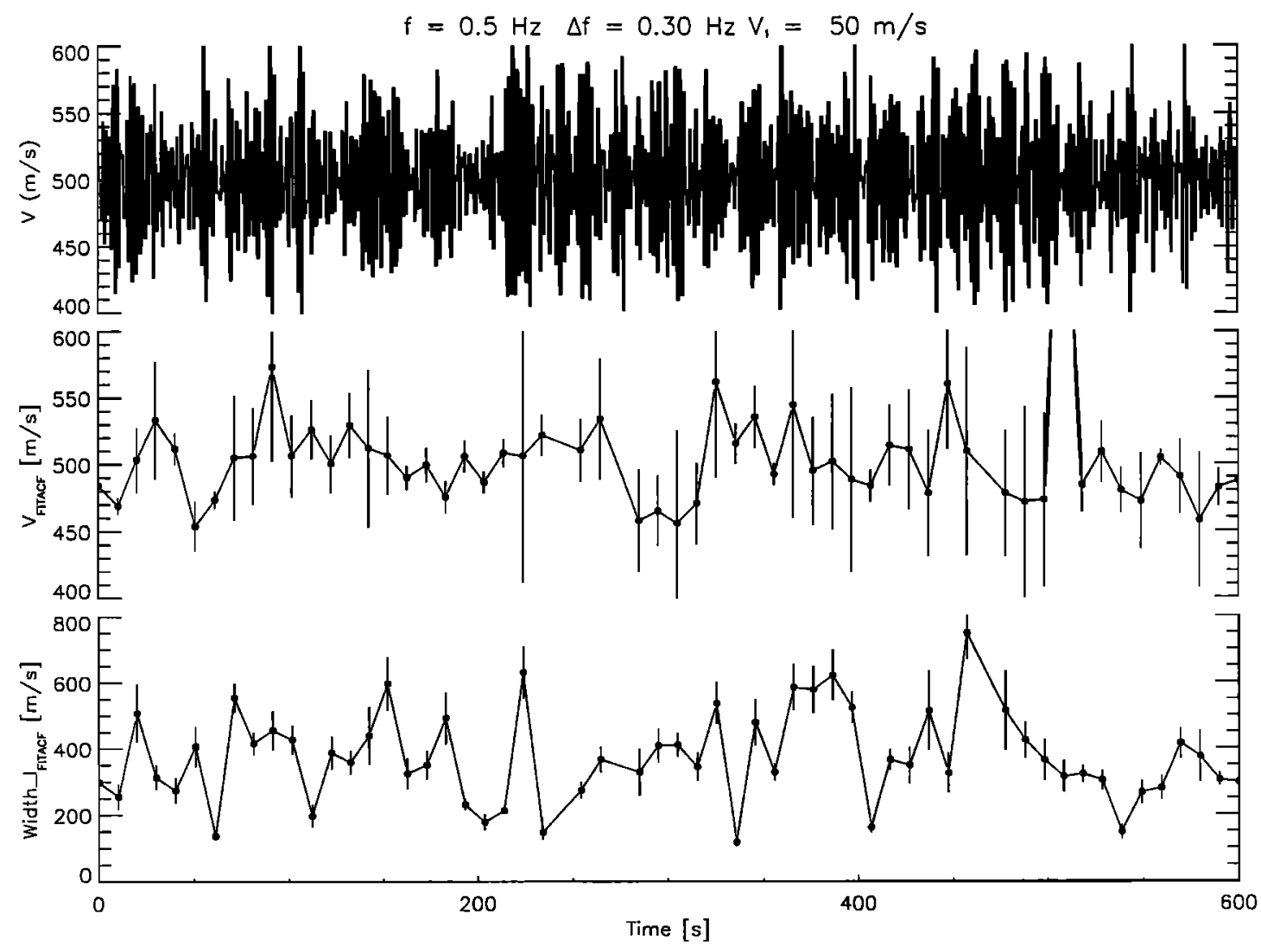

Figure 3. From top to bottom, time series of the wave induced velocity field, simulated line-of-sight velocity field, and spectral width determined from the ACFs. 


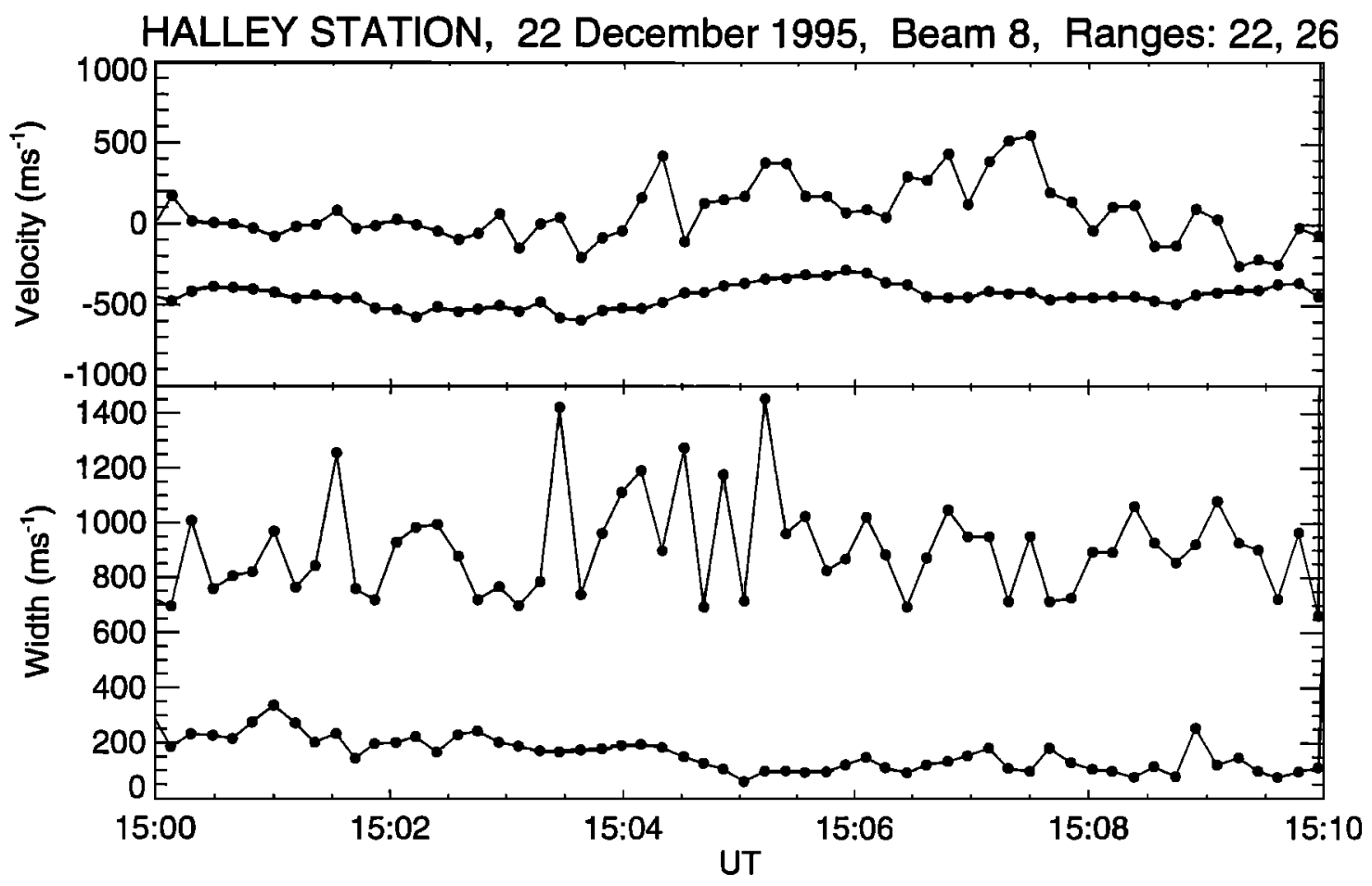

Figure 4. Velocity (upper panel) and spectral width (lower panel) recorded at Halley on December 22, 1995, inside the cusp (upper curve) and equatorward of it (lower curve). The upper curves have been shifted by $500 \mathrm{~m} \mathrm{~s}^{-1}$ for clarity.

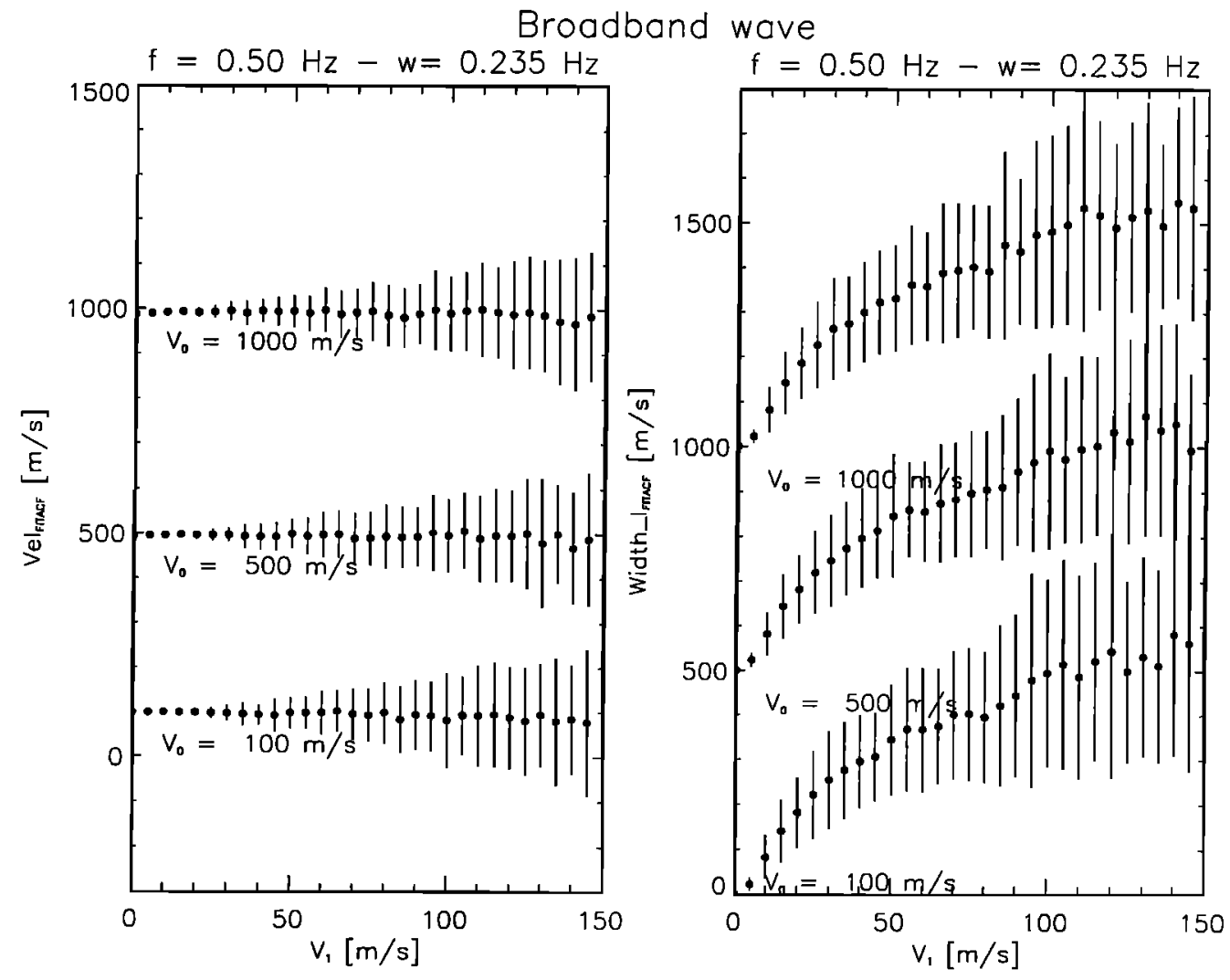

Figure 5. (left) Mean value of the velocity and (right) spectral width. Both values are shown as a function of the wave amplitude and for several background velocities. The error bars give the standard deviations associated with the mean value. 

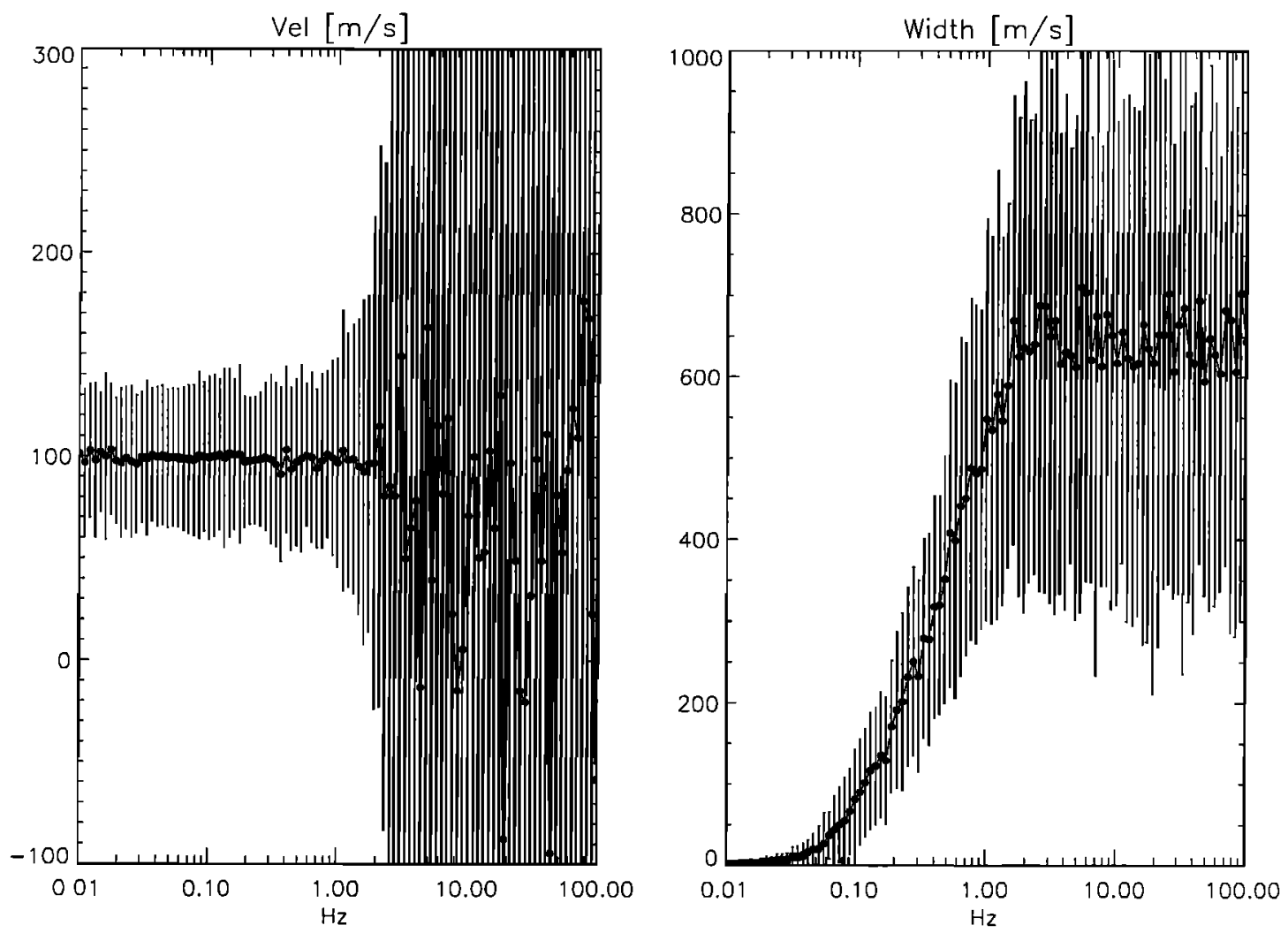

Figure 6. (left) Mean value of the velocity and (right) the spectral width. Both values are shown as a function of the wave amplitude and for wave frequency. The error bars give the standard deviations associated with the mean values.

the wave amplitude (frequency, $0.5 \mathrm{~Hz}$; bandwidth, 0.235 $\mathrm{Hz}$ ), for three background line-of-sight velocities. The error bars represent the standard deviation of these averaged values and so give us an estimate of the velocity fluctuations. The mean velocity does not depend on the wave amplitude. The variations also increase with the wave amplitude, but they are still in the range of the velocity experienced by the scatterers. The conclusion reached is that the mean velocity corresponds to the background velocity whatever the wave amplitude but that the velocity fluctuations increase with the wave amplitude.

Figure 5 (right) shows the spectral width (determined by applying a Lorentzian fit on the ACF power) as a function of the wave amplitude and for the same background velocities as before. One has to note that the curves which correspond to a background velocity of 500 and $1000 \mathrm{~m} \mathrm{~s}^{-1}$ have been shifted by 500 and $1000 \mathrm{~m} \mathrm{~s}^{-1}$, respectively, for clarity. It shows that regardless of the background line-of-sight velocity value, a small wave amplitude $\left(1 \mathrm{mV} \mathrm{m}^{-1}=20 \mathrm{~m} \mathrm{~s}^{-1}\right)$ can result in a spectral width value of $200 \mathrm{~m} \mathrm{~s}^{-1}$ or greater. Again, the fluctuations of the determined spectral width increase with the wave amplitude. This result is very similar to the one found with monochromatic waves.

4.3.3. Wave frequency effect. One can also investigate the variations of these parameters as a function of wave frequency. Here one considers a wave bandwidth equal to 0.1 times the main frequency used. The wave amplitude is 2.5 $\mathrm{mV} \mathrm{m} \mathrm{m}^{-1}\left(50 \mathrm{~m} \mathrm{~s}^{-1}\right)$, and the background velocity is $100 \mathrm{~m}$ $\mathrm{s}^{-1}$.

Figure 6 (left) shows the averaged velocity and its standard deviation as a function of wave frequency. The velocity is constant when the wave frequency is lower than $2 \mathrm{~Hz}$, with a standard deviation which agrees well with the wave amplitude considered. When the wave frequency increases above $2 \mathrm{~Hz}$, the mean velocity starts to be highly variable, with a very large standard deviation, typically greater than $150 \mathrm{~m}$ $\mathrm{s}^{-1}$. This shows that the velocities recorded are no longer representative of the real background velocity of $100 \mathrm{~m} \mathrm{~s}^{-1}$. Howerver, these erroneous velocities can easily be detected by checking their associated error, which is greater than 100 $\mathrm{m} \mathrm{s}^{-1}$, the threshold usually taken when analyzing real radar data [Baker et al., 1995].

Figure 6 (right) shows the mean value of the spectral width as a function of the wave frequency. The spectral width is greater than $150 \mathrm{~m} \mathrm{~s}^{-1}$ for frequencies greater than $0.2 \mathrm{~Hz}$ and sharply increases with frequency until a saturation level is reached. This limitation appears at around 650 $\mathrm{m} \mathrm{s}^{-1}$ for frequencies greater than $\sim 1.3 \mathrm{~Hz}$. Thus, even for a low-amplitude narrowband wave $\left(2.5 \mathrm{mV} \mathrm{m}^{-1}\right)$ in the Pc1-Pc2 frequency band, a high value of spectral width is obtained.

These characteristics are still valid when the wave am- 
plitude varies, but the erroneous velocities and the spectral width saturation at $650 \mathrm{~m} \mathrm{~s}^{-1}$ are obtained for different frequencies, 3 and $2 \mathrm{~Hz}$, respectively, for a wave amplitude of $1.25 \mathrm{mV} \mathrm{m}^{-1}$, or 1 and 0.8 for a wave amplitude of $5 \mathrm{mV}$ $\mathrm{m}^{-1}$.

These results are very similar to those obtained when considering a monochromatic wave. This suggests that the wave bandwidth does not strongly affect these profiles but can only slightly decrease or increase the spectral width because of the differing contribution of the highest frequencies in the wave spectrum.

One can conclude that the results shown in Plate 1 are still valid for a more realistic case. When the saturation level is reached, one can observe a strong increase of the error in the velocity determination.

\section{Discussion}

\subsection{Limitations}

The decay time of the ACF power, quantified by the spectral width, reflects the typical correlation time between irregularity motions under a turbulent electric field. In this simulation the scatterers are randomly distributed over one range gate, and they experience the same electric field. This implies that they keep their coherence all the time, and thus, when considering a steady electric field, the spectral width is expected to be equal to $0 \mathrm{~m} \mathrm{~s}^{-1}$.

It is assumed that there are no structures of the scale size of an HF radar sampling cell (typically $50 \times 100 \mathrm{~km}$ ) in the ionosphere, resulting from smaller-scale and intense precipitations, or static structure in the electric field. These structures would increase the width of the velocity distribution in the radar range gate, and thus they should also increase the spectral width recorded by the radar. Because the same electric field is applied to all irregularities, it is assumed that the wavelength perpendicular to the magnetic field is much greater than the gate length. A smaller wavelength will increase the spatial inhomogeneities and thus the spectral width.

In this simulation the irregularities are uniformly distributed over the whole radar range gate, and their amplitude is constant. Thus the amplitude of the signal backscattered by each irregularity is assumed to be the same. This may not be the case in the $F$ region ionosphere. The irregularities are likely to vary in amplitude within a range gate, and thus the backscattered power is more likely to come from several areas located inside the range gate. By assuming that it is coming mainly from one single area, one could extend this simulation to smaller wavelengths. These limitations imply that the results obtained in this study should be considered as the minimum values of the spectral width recorded by $\mathrm{HF}$ radar in the cusp region.

\subsection{Wave Source}

We have shown that any kind of electric field variation at low altitude (ionospheric $F$ region), in the frequency band 0.1-100 $\mathrm{Hz}$ and with a sufficient amplitude (a few $\mathrm{mV} \mathrm{m}^{-1}$ ) leads to a high spectral width in the SuperDARN radar data. Limitations cited in section 5.1 suggest that the wave should have a wavelength perpendicular to the magnetic field greater than the radar gate length $(45 \mathrm{~km})$. Wave observations in the cusp can generally be described as a superposition of narrowband waves, such as ion cyclotron waves around $1 \mathrm{~Hz}$ and a broadband wave.

5.2.1. Broadband electromagnetic noise. Lowfrequency electromagnetic noise is observed in the auroral zone [Gurnett et al., 1984; Gurnett, 1991]. Electric and magnetic spectra are characterized by a power law, with a magnetic spectrum steeper than the electric one, especially at frequencies greater than $10 \mathrm{~Hz}$. Both electric and magnetic fields are perpendicular to the ambient magnetic field, and the Poynting flux is directed earthward. Several attempts have been made to distinguish between fields from static structures and waves [e.g., Gurnett et al., 1984; Weimer et al., 1985; Berthelier et al., 1991; Heppner et al., 1993].

In the first interpretation (fields from static structures), electric fields are generated by the closure of field-aligned currents in the $E$ region whereas magnetic variations are produced directly by these currents. In this model, the magnetic to electric field ratio is expected to be related to the heightintegrated Pedersen conductivity. In this case the observed wave does not correspond to a temporal variation of the electric field, and thus this wave cannot be used as the energy source of the high radar spectral width.

The noise can also be interpreted as propagating Alfvén waves generated at the magnetopause or in the distant magnetotail. In this case the $E / B$ ratio should be of the order of the local Alfvén wave velocity [Lysak and Dum, 1983]. In a detailed study, Wahlund et al. [1998] have shown that this noise is probably due to a superposition of several wave modes. At the lowest frequencies (below a few tens of hertz) the wave is mainly Alfvénic, as it has been also shown by Chmyrev et al. [1985], Knudsen et al. [1990], Matsuoka et al. [1993], and later by Keady and Heelis [1999].

Similar noise has been recorded within the region of auroral inverted- $V$ electron precipitation and has also been associated with intense events of transverse ion acceleration [e.g., André et al., 1990; Norqvist et al., 1996]. Later, some studies have shown that resonant heating by broadband lowfrequency waves is the dominant ion energization mechanism [André et al., 1998; Knudsen et al., 1998; Norqvist et al., 1998].

5.2.2. Narrowband wave. Narrowband waves at frequencies lower than $10 \mathrm{~Hz}$ are usually referred to as Pc1 waves and have been observed on the ground [e.g., Menk et al., 1992; Dyrud et al., 1997, and references therein], at low altitudes [Iyemori and Hayashi, 1989; Erlandson et al., 1993; Iyemori et al., 1994], high altitudes [Erlandson et al., 1990], and in the equatorial plane of the magnetosphere [Anderson et al., 1992]. This Pc1 wave activity is a persistent feature at ionospheric altitudes over the whole cusp, but its ground signature does not appear so often and seems to be localized on the cusp boundaries only, with a narrowband 
wave near the low-latitude boundary layer and a wideband emission near the poleward edge of the cusp [e.g., Dyrud et al., 1997].

Most of these waves are attributed to electromagnetic ion cyclotron waves generated at the dayside magnetopause in the equatorial plane, which propagate in the slow Alfvén wave mode along the magnetic field lines to the ionosphere [e.g., Basinska et al., 1994]. However, they could be generated during reconnection processes at the magnetopause and propagate along the newly reconnected magnetic field lines. They could also be generated by the reflected cusp ions propagating upward near the poleward edge of the cusp [Dyrud et al., 1997]. These propagating waves could then be reflected by the conducting ionosphere or alternatively by the sharp gradient in the Alfvén velocity found around $1 R_{E}$. This cavity, termed the ionospheric Alfvén resonator, traps Alfvén waves in the frequency range $0.1-1.0 \mathrm{~Hz}$. This implies that waves found at ionospheric altitudes in this frequency band should be composed of a mixture of upgoing and downgoing Alfvén waves [Polyakov and Rapoport, 1981].

Recently, Lysak [1999] modeled Alfvén wave propagation through the ionosphere and showed that waves generated at high altitude can reach the ground when their frequency matches a normal mode of the ionospheric resonator. He also found that the typical perpendicular wavelength is in the range $500-1000 \mathrm{~km}$ in the frequency band $0.5-1 \mathrm{~Hz}$.

5.2.3. High spectral width. These studies show that the low-frequency part of the wave spectrum recorded in the cusp on board low-altitude satellites comprises a superposition of bouncing Alfvén waves and the effect of static field-aligned currents. Because this last component does not imply a temporal variation of the electric field, the Alfvén wave contribution is likely to be the main energy source which gives rise to the high spectral width in the radar data. This is strengthened by their persistent appearance and their large perpendicular wavelength. Because these waves are strongly related to the cusp location, one can conclude that as it has been experimentally shown by Baker et al. [1995], high spectral width in the radar data is a good proxy of the cusp location.

\section{Conclusion}

Identification of the ionospheric signature of the cusp is important since it is a proxy of the open/closed field line boundary on the dayside. By comparison with low-altitude satellite data and optical imagers, Baker et al. [1990, 1995], Rodger et al. [1995] and Yeoman et al. [1997] have experimentally shown that this region is characterized in the HF radar data by a high spectral width. This signature has been extensively used to study the dynamics of the cusp or processes connected with magnetic reconnection [e.g., Pinnock et al., 1995, 1999; Baker et al., 1997; Milan et al., 1999; Greenwald et al., 1999]. However, none of these studies have explained why the spectral width is high in this region.

In this paper we have evaluated the impact of a timevarying electric field in the radar data and especially on the spectral width. We have shown that a narrowband wave in the $\mathrm{Pc} 1$ frequency band, even with a low amplitude, leads to the ACF characteristics observed in the cusp: a great variability in the determined parameters, a spectrum which contains several components, and a high spectral width value. One has to note that this wave activity does not strongly affect the determination of the background electric field and that supplementary components in the recorded Doppler spectrum are caused by the radar technique and may be artefacts.

Because several studies have already shown that such a wave activity is continuously seen in the cusp by lowaltitude satellites [Curtis et al., 1982; Maynard, 1985; Maynard et al., 1991; Matsuoka et al., 1991, 1993; Erlandson and Anderson, 1996] and that its main component at low frequencies could come from downward propagating Alfvén waves, one can conclude that these waves are the main source of the high spectral width observed in the radar data. This wave activity is also observed on magnetic field lines in the auroral oval [Gurnett, 1991]. Thus one can probably use the same mechanism to explain the high spectral widths found over the whole auroral zone, and especially in the nightside where a smooth increase of the spectral width has been associated with the boundary between the central plasma sheet/plasma sheet boundary layer [Dudeney et al., 1998]. Following Gary et al. [1998], this wave activity could also be the signature of the boundaries of large-scale, fieldaligned current systems. We conclude that HF radars are able to reveal sites of wave activity (electromagnetic or electrostatic) in the low-altitude ionosphere and that this potential can be used to map some magnetospheric boundaries.

Acknowledgments. The authors acknowledge helpful discussions with J.-P. Villain and C. Hanuise. This work has been funded by the European Community grant ERB4001GT973635.

Michel Blanc thanks Patrick T. Newell and Nelson C. Maynard for their assistance in evaluating this paper.

\section{References}

Anderson, B.J., R.E. Erlandson, and L.J. Zanetti, A statistical study of Pc1-2 magnetic pulsations in the equatorial magnetosphere, 1, Equatorial occurrence distributions, J. Geophys. Res., 97, 30753088, 1992.

André, M., G.B. Crew, W.K. Peterson, A.M. Persoon, C.J. Pollock, and M.J. Engebretson, Ion heating by broadband low-frequency waves in the cusp/cleft, J. Geophys. Res., 95, 20,809-20,823, 1990.

André, M., P. Norqvist, L. Andersson, A.I. Eriksson, L. Blomberg, R.E. Erlandson, and J. Waldemark, Ion energization mechanisms at $1700 \mathrm{~km}$ in the auroral region, J. Geophys. Res., 103, 41994222, 1998.

André, R., J.-P. Villain, C. Senior, L. Barthes, C. Hanuise, J.C. Cerisier, and A. Thorolfsson, Toward resolving small-scale structures in ionospheric convection from SuperDARN, Radio Sci., 34, 1165-1176, 1999.

Baker, K.B., R.A. Greenwald, J.M. Ruohoniemi, J.R. Dudeney, M. Pinnock, P.T. Newell, M.E. Greenspan, and C.-I. Meng, Simultaneous HF-radar and DMSP observations of the cusp, Geophys. Res. Lett., 17, 1869-1872, 1990.

Baker, K.B., J.R. Dudeney, R.A. Greenwald, M. Pinnock, P.T. Newell, A.S. Rodger, N. Mattin, and C.-I. Meng, HF radar sig- 
natures of the cusp and low-latitude boundary layer, J. Geophys. Res., 100, 7671-7695, 1995.

Baker, K.B., A.S. Rodger, and G. Lu, HF-radar observations of the dayside magnetic merging rate: A Geospace Environment Modeling boundary layer campaign study, J. Geophys. Res., 102, 9603-9617, 1997.

Barthes, L., R. André, J.-C. Cerisier, „and J.-P. Villain, Separation of multiple echoes using a high resolution spectral analysis in SuperDARN HF radars, Radio Sci., 33, 1005-1017, 1998.

Basinska, E.M., W.J. Burke, N.C. Maynard, W.J. Hughes, D.J. Jnudsen, and J.A. Slavin, Electric and magnetic field fluctuations at high-latitudes in the dayside ionosphere during southward IMF, in Solar Wind Sources of Magnetospheric Ultra-LowFrequency Waves, Geophys. Monogr. Ser., vol. 81, edited by M.J. Engebretson, K. Takahashi, and M. Scholer, pp. 387-397, AGU, Washington, D.C., 1994.

Berthelier, A., J.-C. Cerisier, J.-J. Berthelier, and L. Rezeau, Lowfrequency magnetic turbulence in the high-latitude topside ionosphere: Low-frequency waves or field-aligned currents, J. Atmos. Terr. Phys., 53, 333-341, 1991.

Bolshakova, O.B., V.A. Troitskaya, and K.G. Ivanov, High-latitude Pc1-2 geomagnetic pulsations and their connection with location of the dayside polar cusp, Planet. Space Sci., 28, 1-7, 1980.

Chmyrev, V.M., V.N. Oraevsky, S.V. Bilichenko, N.V. Isaev, G.A. Stanev, D.K. Teodosiev, and S.I. Shkolnikova, The fine structure of intensive small-scale electric and magnetic fields in the highlatitude ionosphere as observed by Intercosmos-Bulgaria 1300 satellite, Planet. Space Sci., 33, 1383-1388, 1985.

Curtis, S.A., W.R. Hoegy, L.H. Brace, N.C. Maynard, M. Sugiura, and J.D. Winningham, DE-2 cusp observations: Role of plasma instabilities in topside ionospheric heating and density fluctuations, Geophys. Res. Lett., 9, 997-1000, 1982.

Dudeney, J.R., A.S. Rodger, M.P. Freeman, J. Pickett, J. Scudder, G. Sofko, and M. Lester, The nightside ionospheric response to IMF By changes, Geophys. Res. Lett., 25, 2601-2604, 1998.

Dyrud, L.P., M.J. Engebretson, J.L. Posh, W.J. Hughes, H. Fukunishi, R.L. Amoldy, P.T. Newell, and R.B. Horne, Ground observations and possible source regions of two types of Pcl-2 micropulsation at very high-latitudes, J. Geophys. Res., 102, 27,011-27,027, 1997.

Dyrud, L.P., M.J. Engebretson, J.L. Posh, W.J. Hughes, H. Fukunishi, R.L. Amoldy, and P.T. Newell, Conjugate ground observations and possible source regions of two types of Pcl-2 pulsations at very high-latitudes, in Polar Cap Boundary Phenomena, edited by J. Moen, A. Egeland, and M. Lockwood, pp. 311-326, Kluwer Acad., Norwell, Mass., 1998.

Erlandson, R.E., and B.J. Anderson, Pcl waves in the ionosphere: A statistical study, J. Geophys. Res., 101, 7843-7857, 1996.

Erlandson, R.E., L.J. Zanetti, T.A. Potemra, L.P. Block, and G. Holmgren, Viking magnetic and electric field observations of Pc 1 waves at high-latitudes, J. Geophys. Res., 95, 5941-5955, 1990.

Erlandson, R.E., T.L. Aggson, W.R. Hoegy, and J.A. Slavin, Simultaneous observations of subauroral electron temperature enhancements and electromagnetic ion cyclotron waves, Geophys. Res. Lett., 20, 1723-1726, 1993.

Gary, J.B., L.J. Zanetti, B.J. Anderson, T.A. Potemra, J.H. Clemmons, J.D. Winningham, and J.R. Sharber, Identification of auroral oval boundaries from in situ magnetic field measurements, J. Geophys. Res., 103, 4187-4197, 1998.

Greenwald, R.A., K.B. Baker, R.A. Hutchins, and C. Hanuise, An HF phased array radar for studying small-scale structure in the high-latitude ionosphere, Radio Sci., 20, 63-79, 1985.

Greenwald, R.A., W.A. Bristow, G.J. Sofko, C. Senior, J.-C. Cerisier, and A. Szabo, Super Dual Auroral Radar Network radar imaging of dayside high-latitude convection under northward interplanetary magnetic field: Toward resolving the distorted twocell versus multicell controversy, J. Geophys. Res., 100, 19,661$19,674,1995$.
Greenwald, R.A., J.-M. Ruohoniemi, K.B. Baker, W.A. Bristow, G.J. Sofko, J.-P. Villain, M. Lester, and J. Slavin, Convective response to a transient increase in dayside reconnection, J. Geophys. Res., 104, 10,007-10,015, 1999.

Gumett, D.A., Auroral plasma waves, in Auroral Physics, edited by C.-I. Meng, M.J. Rycroft, and L.A. Franck, chap. IV-6, pp. 241-254, Cambridge Univ. Press, New York, 1991.

Gurnett, D.A., R.L. Huff, J.D. Menietti, J.L. Burch, J.D. Winningham, and S.D. Shawhan, Correlated low-frequency electric and magnetic noise along the auroral field lines, J. Geophys. Res., 89, 8971-8985, 1984.

Heppner, J.P., M.C. Liebrecht, N.C. Maynard, and R.F. Pfaff, Highlatitude distribution of plasma waves and spatial irregularities from DE 2 alternating current electric field observations, J. Geophys. Res., 98, 1629-1652, 1993.

Iyemori, T., and K. Hayashi, $\mathrm{Pcl}$ micropulsations observed by MAGSAT in the ionospheric $F$ region, J. Geophys. Res., 94, 93$100,1989$.

Iyemori, T., M. Sugiura, A. Oka, Y. Morita, M. Ishii, J.A. Slavin, L.H. Brace, R.A. Hoffman, and J.D. Winningham, Localized injection of large amplitude Pc1 waves and electron temperature enhancement near plasmapause observed by DE 2 in the upper ionosphere, J. Geophys. Res., 99, 6187-6199, 1994.

Keady, J.P., and R.A. Heelis, Regional, scale size, and interplanetary magnetic field variability of magnetic field and ion drift structures in the high-latitude ionosphere, J. Geophys. Res., 104, 199-212, 1999.

Knudsen, D.J., M.C. Kelley, G.D. Earle, J.F. Vickrey, and M. Boehm, Distinguishing Alfvén waves from quasi-static field structures associated with the discrete aurora: Sounding rocket and HILAT satellite measurements, Geophys. Res. Lett., 17, 921-924, 1990.

Knudsen, D.J., J.H. Clemmons, and J.-E. Wahlund, Correlation between ion energization, suprathermal electron burst, and broadband ELF plasma waves, J. Geophys. Res., 103, 4171-4186, 1998.

Lysak, R.L., Propagation of Alfvén waves throughout the ionosphere: Dependence on ionospheric parameters, J. Geophys. Res., 104, 10,017-10,030, 1999.

Lysak, R.L., and C.T. Dum, Dynamics of magnetosphereionosphere coupling including turbulent transport, J. Geophys. Res., 88, 365-380, 1983.

Matsuoka, A., T. Mukai, H. Hayakawa, Y.-I. Kohno, K. Tsuruda, A. Nishida, T. Okada, N. Kaya, and-H. Fukinishi, EXOS-D observations of electric field fluctuations and charged particle precipitation in the polar cusp, Geophys. Res. Lett., 18, 305-308, 1991.

Matsuoka, A., K. Tsuruda, H. Hayakawa, T. Mukai, A. Nishida, T. Okada, N. Kaya, and H. Fukunishi, Electric field fluctuations and charged particle precipitation in the cusp, J. Geophys. Res., 98, 11,225-11,234, 1993.

Maynard, N.C., Structure in the DC and AC electric fields associated with the dayside cusp region, in The Polar Cusp, edited by J.A. Holtet and A. Egeland, pp. 305-322, D. Reidel, Norwell, Mass., 1985.

Maynard, N.C., T.L. Aggson, E.M. Basinka, W.J. Burke, P. Craven, W.K. Peterson, M. Sugiura, and D.R. Weimer, Magnetospheric boundary dynamics: DE-1 and DE-2 observations near the magnetopause and cusp, J. Geophys. Res., 96, 3505-3522, 1991.

Menk, F.W., B.J. Fraser, H.J. Hansen, P.T. Newell, C.-I. Meng, and R.J. Morris, Identification of the magnetospheric cusp and cleft using Pcl-2 ULF pulsations, J. Atmos. Terr. Phys., 54, 10211042, 1992.

Milan, S.E., M. Lester, S.W.H. Cowley, J. Moen, P.E. Sandholt, and C.J. Owen, Meridian-scanning photometer, coherent HF radar, and magnetometer observations of the cusp: a case study, Ann. Geophys., 17, 159-172, 1999.

Morris, R.J., and K.D. Cole, High-latitude Pcl-2 continuous mag- 
netic pulsations: A ground signature of the polar cusp and cleft projection, Planet. Space Sci., 39, 1473-1491, 1991.

Newell, P.T., and C.-I. Meng, The cusp and the cleft/boundary layer: Low-altitude identification and statistical local time variation, J. Geophys. Res., 93, 14,549-14,556, 1988.

Newell, P.T, and C.-I. Meng, Dipole tilt angle effects on the latitude of the cusp/cleft/LLBL, J. Geophys. Res., 94, 6949-6954, 1989.

Newell, P.T., and C.-I. Meng, Mapping the dayside ionosphere to the magnetosphere according to particle precipitation characteristics, Geophys. Res. Lett., 19, 609-612, 1992.

Newell, P.T., C.-I. Meng, D.G. Sibeck, and R.P. Lepping, Some low-altitude cusp dependencies on the interplanetary magnetic field, J. Geophys. Res., 94, 8921-8927, 1989.

Norqvist, P., M. André, L. Eliasson, A.I. Eriksson, L. Blomberg, H. Lühr, and J.H. Clemmons, Ion cyclotron heating in the dayside magnetosphere, J. Geophys. Res., 101, 13,179-13,193, 1996.

Norqvist, P., M. André, and M. Tyrland, A statistical study of ion energization mechanism in the auroral region, J. Geophys. Res., 103, 23,459-23,473, 1998.

Pinnock, M., A.S. Rodger, J.R. Dudeney, F. Rich, and K. Baker, High-spatial and temporal observations of the ionospheric cusp, Ann. Geophys., 13, 919-925, 1995.

Pinnock, M., A.S. Rodger, K.B. Baker, G. Lu, and M. Hairston, Conjugate observations of the day-side reconnection electric field: A GEM boundary layer campaign, Ann. Geophys., 17, 443-454, 1999.

Polyakov, S.V., and V.O. Rapoport, Ionospheric Alfvén resonator, Geomagn. Aeron., 21, 816-822, 1981.
Rodger, A.S., S.B. Mende, T.J. Rosenberg, and K.B. Baker, Simultaneous optical and HF radar observations of the ionospheric cusp, Geophys. Res. Lett., 22, 2045-2048, 1995.

Villain, J.-P., R.A. Greenwald, K.B. Baker, and J.M. Ruohoniemi, HF radar observations of E-region plasma irregularities produced by oblique electron streaming, $J$. Geophys. Res., 92, 12,327$12,342,1987$.

Wahlund, J.-E., et al., Broadband ELF plasma emission during auroral energization, 1, Slow ion acoustic waves, J. Geophys. Res., 103, 4343-4375, 1998.

Weimer, D.R., C.K. Goertz, D.A. Gurnett, N.C. Maynard, and J.L. Burch, Auroral zone electric fields from DE 1 and 2 at magnetic conjunctions, J. Geophys. Res., 90, 7479-7494, 1985.

Yeoman, T.K., M. Lester, S.W.H. Cowley, S.E. Milan, J. Moen, and P.E. Sandholt, Simultaneous observations of the cusp in optical, DMSP and HF radar data, Geophys. Res. Lett., 24, 2251-2254, 1997.

R. André, Laboratoire de Physique et Chimie de l'Environnement, Centre National de la Recherche Scientifique, 3A, Av. de la Recherche Scientifique, 45071 Orléans cedex, France, (raandre@cnrs-orleans.fr).

M. Pinnock, and A. S. Rodger, British Antarctic Survey, High Cross, Madingley Road, Cambridge CB3 OET, England

(Received November 29, 1999; revised March 23, 2000; accepted May 1, 2000.) 